\title{
1 Toward an integrated root ideotype for irrigated systems
}

2 Jennifer E. Schmidt ${ }^{1}$ and Amélie C.M. Gaudin ${ }^{*}, 1$

3

$4 \quad{ }^{1}$ Department of Plant Sciences, University of California, Davis. Davis, CA, USA 95616.

5 *agaudin@ucdavis.edu (A. Gaudin), http://gaudin.ucdavis.edu/, @ amelie_gaudin

6

7

8

9

10

11

12

13

14

Keywords: ideotypes, irrigated agriculture, micro-irrigation, roots, rhizosphere

15

16

(C) 2017. This manuscript version is made available under the Elsevier user license

http://www.elsevier.com/open-access/userlicense/1.0/ 
18 Breeding towards root-centric ideotypes can be a relatively quick trait-based strategy to 19 improve crop resource use efficiency. Irrigated agriculture represents a critical and 20 expanding sector, but its unique parameters require traits distinct from previously 21 proposed rainfed ideotypes. We propose a novel irrigated ideotype that integrates traits 22 across multiple scales to enhance resource use efficiency in irrigated agroecosystems, where 23 resources are concentrated in a relatively shallow "critical zone". Unique components of 24 this ideotype include rapid transplant recovery and establishment, enhanced exploitation of 25 localized resource hotspots, adaptive physiological regulation, maintenance of hydraulic conductivity, beneficial rhizosphere interactions, and salinity/waterlogging avoidance. If augmented by future research, this target could help enhance agricultural sustainability in irrigated agroecosystems by guiding the creation of resource-efficient cultivars.

31 Increasing resource use efficiency requires a novel root ideotype tailored to irrigated 32 systems If current water use efficiency (WUE) (Glossary) does not increase, irrigated land area is 34 projected to increase 40 million ha by 2030 and water needs by $20 \%$ by 2050 to sustain food 35 production required for a growing population [1-6]. Many economically and nutritionally 36 important fruit and vegetable crops are produced in irrigated agroecosystems located in arid and 37 semi-arid climates with scarce, unreliable water resources. Given tight linkages between 38 irrigation water management, nutrient cycling and yields in irrigated systems [7], improving 39 water productivity is critical to sustain healthy, productive food systems while decreasing 40 pressure on the environment and limited water supplies in a changing climate [8]. 
Breeding resource-efficient cultivars could complement improvements in irrigation

42 technology such as micro-irrigation [9] to maintain the sustainability of irrigated agriculture in

43 an uncertain future. Root-based approaches present untapped potential to create cultivars adapted

44 to the unique resource environment of irrigated crops as most research has been directed toward 45 exploiting root traits to enhance nitrogen, water, and phosphorus use efficiency in rainfed

46 systems [10]. We argue that rainfed root ideotypes likely do not translate to the unique irrigated

47 context and that addressing architectural and morphological traits without sufficient attention to

48 rhizosphere functions [11,12] fosters incomplete understanding of beneficial root traits for

49 specific soil and management practices and genotype-specific response to environmental cues. A

50 novel root ideotype for irrigated annual crops, which integrates a large suite of architectural,

51 morphological, physiological, and biotic traits is critically needed to enhance agricultural

52 productivity and decouple the necessary intensification from environmental degradation. This

53 ideotype can guide development of resource-efficient cultivars adapted to irrigated

54 agroecosystems which better capture costly water inputs, reduce the environmental footprint of

55 irrigated agricultural landscapes, and dynamically cope with limiting nutrient resources or acute

56 shortages in irrigation water.

58 The unique irrigated environment

Previous discussions of beneficial root traits $[11,13,14]$ and ideotypes for rainfed systems

60 [15] have greatly contributed to our understanding of root functions and mechanisms essential to

61 efficiently capture resources. A frequently cited rainfed-environment ideotype to enhance cereal

62 foraging and acquisition of water and mobile nutrients combines steep root angle, deep taproot

63 development, unresponsive lateral branching and low metabolic investment (Key Figure 1) 
$64[10,15]$. Although this ideotype offers useful insights into the importance of individual phenes

65 and their interactions, rainfed ideotypes do not necessarily translate to irrigated systems where

66 temporal and spatial resource dynamics differ at the system, field, and rhizosphere scales.

67 First, root ideotype models developed to perform under resource-limited rainfed

68 conditions $[15,16]$ may not suit intensive irrigated environments, where nutrients rarely limit

69 productivity [17] and where costly inputs are precisely delivered to surface or shallow subsurface

70 soil to minimize losses below the root zone. The intensive nature of irrigated agriculture

71 therefore likely incentivizes uptake efficiency over foraging and alleviates the need for

72 metabolically inexpensive roots, which may present tradeoffs for transport (Box 1) [18].

73 Drastic differences in the location and dynamics of resource availability between

74 irrigated and rainfed systems [19] also call for ideotypes emphasizing localized responses to

75 resource distribution rather than foraging strategies based on nutrient mobility. More targeted,

76 predictable and frequent water inputs than precipitation during the growing season result in less

77 intense wet-dry cycles which affect nutrient cycling and mineralization $[20,21]$ and may favor

78 constant over pulsed resource availability. Still, attempts at a conclusive summary of differences

79 in duration and intensity of wet-dry cycles between rainfed and irrigated systems are confounded

80 by the irrigation technology implemented and scale- and site-dependent characteristics (Box 2).

81 Fertigation or multiple targeted fertilizer applications throughout the growing season are also

82 common practices to improve nitrogen use efficiency (NUE) [22,23] and nutrients, especially

83 immobile $\mathrm{P}$ remain concentrated where applied in micro-irrigated and fertigated systems [23-

84 25]. Best management strategies that reduce runoff and leaching thus create resource-rich

85 hotspots near the root zone where plasticity, root physiological activity, and rhizosphere

86 interactions become critical to resource use efficiency. Local root proliferation coupled with 
87 high uptake rates to mine this critical zone may therefore be more favorable than the foraging 88 strategies suggested by earlier models [26]. Although simulations of root system development 89 are now complex, dynamic, and optimized for capture of both mobile and immobile nutrients 90 [27], they remain focused on large-scale soil exploration to capture the more ephemeral and 91 dispersed resources of rainfed systems. In addition, repeated wetting and evaporation of saline 92 irrigation water creates localized waterlogging and salt accumulation and inclusion of root traits 93 conferring salinity and waterlogging tolerance in the irrigated ideotype is critical to avoid yield 94 reductions.

95 Rhizosphere biological processes and the outcomes of microbe-mediated carbon and 96 nitrogen cycling [28] are also affected by agroecosystem properties and management practices

97 that differ between rainfed and irrigated systems and must be better integrated with other root 98 phenes to develop comprehensive ideotypes (Box 3). Irrigated soils in arid climates typically 99 have lower organic carbon contents [29] and low precipitation de-incentivizes organic matter 100 additions to improve water retention and infiltration. Reduction in available substrates [30] 101 combined with intensive management could diminish populations of disturbance-sensitive 102 microbes in bulk and rhizosphere soils [31] and their contribution to crop nutrition and 103 productivity.

104 These altered agroecosystem properties highlight the need for a unique and more 105 integrated root ideotype for irrigated systems. Here we reconcile sparse knowledge of root 106 system response to irrigated environments with fundamental differences in soil water and 107 nutrient resource dynamics between rainfed and irrigated systems to conceptualize key 108 components of this novel ideotype and identify knowledge gaps and future research needs. 


\section{Toward an integrated ideotype for irrigated agriculture}

111 Integrating morphological traits with root eco-physiological properties to achieve resource

112 use efficiency is a novel approach to develop functionality-oriented root ideotypes tailored to

113 specific agroecosystems (Box 1). We propose that in irrigated systems, desirable root functions

114 confer rapid transplant recovery and include efficient proliferation and plasticity in resource-rich

115 patches, high physiological plasticity and hydraulic conductivity, promotion of rhizosphere

116 interactions, and tolerance to salinity and waterlogging (Figure 1).

118 Rapid transplant recovery and vigorous establishment

119 Vigorous germination, rapid root elongation and cold tolerance, which help rainfed crops 120 establish in low temperature spring soils, are likely less relevant in irrigated systems where 121 seedlings are transplanted into warm soils and yield is mostly affected by transplanting depth 122 [32]. Therefore, the irrigated ideotype requires transplant recovery through early carbon 123 allocation to basal roots [33], extensive micronutrient uptake to meet increased needs early in

124 development [34], and abiotic stress tolerance. Although rapid axial root elongation may remain 125 beneficial to capture resources delivered deeper in the soil profile, early lateral proliferation to 126 exploit the wetting zone may be more advantageous for low-cost resource acquisition. Although 127 not experimentally confirmed, these traits may allow faster transplant recovery, earlier canopy 128 development and ultimately enhance WUE and yields by maximizing carbon capture throughout 129 the crop growth period [35]. 
132 The irrigated ideotype ideally combines few axial roots at varied angles from the main stem and

133 highly plastic root proliferation in the shallow wetting zone via extensive, responsive lateral

134 branching to help crops efficiently acquire concentrated resources and minimize leaching losses

$135[36,37]$.

136 At the macro scale ( $\mathrm{m}$ to $\mathrm{cm}$ ), few axial roots at more obtuse angles rather than uniformly

137 steep could help maximize resource acquisition at a minimal metabolic cost. Irrigated field

138 studies have shown preferential investment in shallow rooting and root length density (RLD)

139 tends to decrease rapidly with soil depth and lateral distance from the water source $[38,39]$.

140 Early-developing shallow axial roots with extensive lateral branching could maximize uptake of

141 banded pre-plant $\mathrm{N}$ and help capture multiple $\mathrm{N}$ surface applications throughout the season while

142 few steeper-angled axial roots could increase capture of mobile resources leaching past the 143 wetting zone [40] and increase anchorage [17].

144 At the meso scale ( $\mathrm{cm}$ to $\mathrm{mm}$ ), lateral root plasticity in response to resource heterogeneity 145 would allow plants to rapidly exploit shallow irrigation-system-specific wetting zones and 146 nutrient-rich patches [41]. Irrigation timing and frequency constantly shape the wetting zone, in

147 turn affecting the location of maximum RLD and triggering roots to elongate towards the moving 148 moisture boundary $[38,39,42]$. This lateral root phenotype could play a leading role in adaptive 149 plasticity by allowing small spatial scale proliferation at low metabolic cost and support the 150 majority of root hairs [43]. While they primarily facilitate acquisition of immobile nutrients in 151 rainfed topsoils [44], shallow foraging accesses both mobile and immobile resources in irrigated 152 systems. Responsive lateral root proliferation and higher specific root length [45] in the wetting 153 zone would likely be beneficial. Nonetheless, metabolically cheap, localized lateral root 154 plasticity can incur multiple tradeoffs and advantages must be thoroughly assessed (Box 1). 
Micro-scale (mm to um) strategies such as root hair development could help address some of

156 these tradeoffs by compensating for reduced proliferation by increasing uptake and use

157 efficiency of immobile nutrients per unit root length [46-48]. Long, dense root hairs can also

158 enhance root ability to penetrate non-compacted soils [49] and increase surface area for uptake

159 and microbial interactions. Since root hair length is a plastic trait [50], responsiveness rather than

160 constitutive expression might be advantageous to lower specific root respiration and increase

161 biomass accumulation [50].

163 Adaptive physiological regulation

164 Long-lived roots and rapidly inducible water and nutrient transporters to enhance plasticity of 165 nutrient uptake per unit root length and better match wet-dry cycles [51] may be important traits 166 to consider for a resource-efficient ideotype adapted to resource dynamics in irrigated systems.

167 Induction of nutrient transporters allows quicker exploitation of heterogeneous resources with 168 fewer tradeoffs than growth and proliferation responses [45]. For rainfed maize, maximum 169 nitrate uptake rates $\left(\mathbf{V}_{\mathbf{m a x}}\right)$ and transporter affinities $\left(\mathbf{K}_{\mathbf{m}}\right)$ vary by root type and $\mathrm{V}_{\max }$ has a 170 greater effect on uptake and shoot growth [52]. In irrigated systems, lateral root development 171 combined with high $\mathrm{V}_{\max }$ could improve $\mathrm{N}$ acquisition. Yet manipulating nitrate and ammonium

172 transporter expression has been investigated in model species and extensive feedback regulation 173 mechanisms exist $[44,53]$. As NUE depends on soil $\mathrm{N}$ concentrations, benefits may vary with $\mathrm{K}_{\mathrm{m}}$ 174 of the transporter apparatus. A flexibility-based strategy incorporating inducible and cell-specific 175 transporter activation along the roots might be more beneficial. Emphasizing low $\mathrm{K}_{\mathrm{m}}$ would 176 likely aid immobile nutrient acquisition more than high $\mathrm{V}_{\max }$ due to depletion in the root-dense 
177 wetting zone and restricted lateral foraging. Likewise, plastic aquaporin regulation could aid

178 rapid physiological adaptation to changing soil water conditions [10].

179 Root turnover is an important yet often overlooked physiological trait in annual crops and

180 rapid turnover can accompany high proliferation in nutrient-rich patches [54]. However, studies

181 have found increases in longevity of newly initiated roots in fertile patches [55] and frequent

182 turnover may be disadvantageous due to construction costs under resource-scarce conditions

183 such as the edge of the wetting zone [56] (Box 1). Integrating measurements of nutrient uptake

184 and maintenance costs for each root type with turnover rates could show whether increased

185 mortality in combination with the proliferation response is more adaptive than proliferation

186 alone. In fertilized, irrigated agroecosystems with predictable nutrient availability, long-lived,

187 highly vesseled roots might be beneficial for hydraulic conductance [57] and efficient nutrient

188 uptake since transport costs are minimal relative to root construction and maintenance [58].

190 Maintaining hydraulic conductivity in a heterogeneous environment

191 High rhizosphere hydraulic conductivity through morphological and physiological

192 strategies including long, dense root hairs and mucilage production could help irrigated crops

193 maintain water and dissolved nutrient uptake during expansions and contractions of the wetting

194 zone. While rhizosphere hydraulic conductivity could also improve yields in rainfed systems

195 with irregular precipitation events, small scale rapid and regular shifts in the extent and

196 morphology of the wetting zone may accentuate the importance of these traits in irrigated

197 systems. Genotypes with greater root hair length could potentially increase hydraulic

198 conductivity by decreasing resistance at the soil-root interface that restricts maximal water

199 utilization [59] and enhance irrigation water capture since root hairs create larger depletion zones 
200 in drying soils [60] and increase soil-water contact and surface area for uptake. Studies suggest

201 that root hair length is more important for acquisition of water and other resources and less

202 sensitive to soil moisture conditions than the density of root hairs along the main root $[61,62]$.

203 Increased hydraulic contact generated by mucilage could also be a relatively low-cost strategy to

204 maintain root-water contact and thus maximize WUE as mucilage increases rhizosphere water

205 content and root-soil contact during drying [63-65] with significant impacts on plant

206 performance under dry conditions [66].

208 Fostering rhizosphere interactions

209 Under intensive irrigated conditions, microbial effects on soil structure may be more

210 important than for nutrient cycling and acquisition (Box 3). Enhanced rhizosphere soil

211 aggregation and porosity through organic matter metabolism and exopolysaccharide production

212 [67] can help roots maintain rhizosphere hydraulic conductivity and maximize water uptake.

213 Ideotypes which foster mycorrhizal symbioses may also benefits as arbuscular mycorrhizal fungi

214 (AMF) improve soil structure, access and transport water through hyphal networks, and modify

215 root hydraulic conductance, aquaporin expression, abscisic acid (ABA) production, root-growth-

216 promoting phytohormones, and plant nutritional status [68-71]. This might be especially relevant

217 under deficit or suboptimal irrigation scenarios in which mycorrhizal plants can access a greater

218 proportion of applied water, improving uptake, drought resistance, and ultimately yield resilience

219 [72]. Bacteria that produce ACC deaminase can also prevent drought-induced yield reductions

220 through local and systemic pathways [73] and affect plant phenotypic plasticity by direct abiotic

221 stress alleviation or modulation of developmental pathways [74]. However, the utility of

222 microbial associations for breeding programs and ideotypes development is currently 
223 compromised by a lack of knowledge of genetic variation and heritability of microbe-related host

224 root traits and further research is required (Box 3).

225

226 Coping with salinity and waterlogging

227 Since roots are concentrated in shallow soils where water-filled pore space and salinity are

228 highest, an irrigated root ideotype must possess physiological and morphological traits to 229 minimize structural and physiological damage from hypoxia, salinity and their interactions.

230 Inducible development of adventitious roots with cortical aerenchyma, endodermal barriers

231 and heightened sodium exclusion mechanisms [75,76] could be beneficial in irrigated saline

232 soils. Extensive development of short adventitious roots and subsequent aerenchyma formation

233 can provide alternative airflow pathways that prevent hypoxic root conditions as shown in

234 natural systems with waterlogging cycles such as mangrove swamps [76] while providing axial

235 support for lateral branching once optimal conditions resume. Development of a barrier to

236 restrict radial oxygen and water loss [76,77] and sodium exclusion through selective uptake and

237 loading into root xylem vessels, or removal from the xylem at the root-shoot boundary [78] could

238 avoid yield reductions due to salinity-waterlogging interactions. Salinity tolerance may be most

239 important later in the season and in shallow soils where salts accumulate.

\section{Concluding Remarks and Future Perspectives}

242 There is an urgent need to investigate crop root development and beneficial traits to enhance

243 water use efficiency of irrigated systems by increasing yields under constant or reduced water

244 inputs [79]. The novel ideotype proposed here (Figure 1) integrates traits contributing to resource 245 use efficiency across scales, emphasizes adaptive acquisition in the resource-concentrated critical 
zone unique to the irrigated environment and lay the foundation for research on specific phenes.

247 Future research exploring crop- and irrigation-system-specific traits and the poorly understood

248 interactions with soil ecology and functions could significantly contribute to the development of

249 an irrigated ideotype and guide breeding efforts (Outstanding Questions). Ideotype breeding can

250 provide more rapid gains than yield-based selection in limiting environments [10] and breeding

251 toward a novel irrigated ideotype could provide a faster, targeted strategy to enhance the

252 sustainability of irrigated agriculture. This will be conditioned by our ability to move away from

253 snapshot measurements of coarse variables such as RLD and biomass which have limited ability

254 to predict resource acquisition, plasticity and yield [40,80]. Imaging technologies [81,82], which

255 have recently exposed artifacts of previous methodology [42], coupled with genotyping provide

256 unprecedented prospects to study morphological, and temporal variability in root response to

257 efficient irrigation technologies. This will help identify beneficial root and rhizosphere traits,

258 their interaction and the underlying genetic basis and variability available for breeding. Although

259 these techniques remain to be adapted to irrigated systems [66], they could vastly improve our

260 ability to harness belowground structures while creating positive feedback loops to

261 agroecosystem functions essential to sustainability and resilience of irrigated systems. Roots

262 acquire resources but also sequester carbon and therefore mediate critical ecosystem functions

263 essential to agricultural sustainability and climate change adaptation and mitigation.

265 Acknowledgements

The authors would like to acknowledge the University of California, Davis and the College of Agricultural and

Environmental Sciences for a Graduate Scholars Fellowship to JS and for research funds through the CAES

Programmatic Initiative to AG. This work was partially funded by the Foundation for Food and Agriculture 


\section{References}

1 Lobell, D.B. et al. (2008) Prioritizing Climate Change Adaptation Needs for Food Security in 2030. Science 319, 607-610

2 Döll, P. and Siebert, S. (2002) Global modeling of irrigation water requirements. Water Resour. Res. 38, 8-1

3 Hanjra, M.A. and Qureshi, M.E. (2010) Global water crisis and future food security in an era of climate change. Food Policy 35, 365-377

4 WWDR Water and Energy: Facts and Figures. . (2014), The United Nations World Water Development Report

5 FAO Agriculture, Food and Water. . (2003)

6 Elliott, J. et al. (2014) Constraints and potentials of future irrigation water availability on agricultural production under climate change. Proc. Natl. Acad. Sci. 111, 3239-3244 cycle and budget: A review. Agric. Water Manag. 178, 225-238

8 Molden, D. et al. (2010) Improving agricultural water productivity: Between optimism and caution. Agric. Water Manag. 97, 528-535

9 ICID (2016), Sprinkler and Micro irrigated area in the World., International Commission on Irrigation and Drainage. [Online]. Available: http://www.icid.org/icid_data.html. [Accessed: 18-Aug-2016]

10 Watt, M. et al. (2013) Root-Based Solutions to Increasing Crop Productivity. In Plant Roots: The Hidden Half (4th edn) pp. 21.1-21.17, CRC Press

11 Araus, J.L. et al. (2002) Plant breeding and drought in C-3 cereals: What should we breed for? Ann. Bot. 89, 925-940

12 Lynch, J.P. et al. (2014) Root anatomical phenes associated with water acquisition from drying soil: targets for crop improvement. J. Exp. Bot. 65, 6155-6166

13 Witcombe, J.R. et al. (2008) Breeding for abiotic stresses for sustainable agriculture. Philos. Trans. R. Soc. B-Biol. Sci. 363, 703-716

14 Lilley, J.M. and Kirkegaard, J.A. (2016) Farming system context drives the value of deep wheat roots in semi-arid environments. J. Exp. Bot. 67, 3665-3681

15 Lynch, J.P. (2013) Steep, cheap and deep: an ideotype to optimize water and $\mathrm{N}$ acquisition by maize root systems. Ann. Bot. 112, 347-357

$16 \mathrm{Mi}$, G. et al. (2010) Ideotype root architecture for efficient nitrogen acquisition by maize in intensive cropping systems. Sci. China Life Sci. 53, 1369-1373

17 Mi, G. et al. (2016) Ideotype Root System Architecture for Maize to Achieve High Yield and Resource Use Efficiency in Intensive Cropping Systems. Adv. Agron. 139, 73-97

$18 \mathrm{Hu}, \mathrm{B}$. et al. (2014) Root cortical aerenchyma inhibits radial nutrient transport in maize (Zea mays). Ann. Bot. 113, 181-189

19 Ryan, J. et al. (2009) Nitrogen in Rainfed and Irrigated Cropping Systems in the Mediterranean Region. Adv. Agron. 104, 53-136 
20 Borken, W. and Matzner, E. (2009) Reappraisal of drying and wetting effects on C and N mineralization and fluxes in soils. Glob. Change Biol. 15, 808-824

21 Banerjee, S. et al. (2016) Legacy effects of soil moisture on microbial community structure and N2O emissions. Soil Biol. Biochem. 95, 40-50

22 Capurro, M.C. and Sawchik, J. (2015) Nitrogen fertilization in Maize under Irrigated and Rainfed Conditions. Agrociencia 19, 21

23 Olson, J.R. (2011), Phosphorus fertilization of corn using subsurface drip irrigation. , Thesis, Kansas State University

24 Fontanetto, H. and Darwich, N. (1995) Effects of Phosphorus Placement for Corn with and without Irrigation. Better Crops 79, 26-27

25 He, Z. et al. (2011) Irrigation-Induced Changes in Phosphorus Fractions of Caribou Sandy Loam Soil Under Different Potato Cropping Systems. Soil Sci. 176, 676-683

26 Fitter, A.H. (1985) Functional significance of root morphology and root system architecture. In Ecological Interactions in Soil pp. 87-106, Blackwell Scientific Publications

27 Zhu, X.-G. et al. (2016) Plants in silico: why, why now and what?an integrative platform for plant systems biology research. Plant Cell Environ. 39, 1049-1057

28 Rietz, D.N. and Haynes, R.J. (2003) Effects of irrigation-induced salinity and sodicity on soil microbial activity. Soil Biol. Biochem. 35, 845-854

29 Jobbagy, E.G. and Jackson, R.B. (2000) The vertical distribution of soil organic carbon and its relation to climate and vegetation. Ecol. Appl. 10, 423-436

30 Smaill, S.J. et al. (2009) Legacies of organic matter removal: decreased microbial biomass nitrogen and net $\mathrm{N}$ mineralization in New Zealand Pinus radiata plantations. Biol. Fertil. Soils 46, 309-316

31 Frey, S.D. et al. (1999) Bacterial and fungal abundance and biomass in conventional and no-tillage agroecosystems along two climatic gradients. Soil Biol. Biochem. 31, 573-585

32 Almasoum, A.A. (2000) Effect of planting depth on growth and productivity of tomatoes using drip irrigation with semi saline water. Acta Hortic. 537, 773-778

33 Leskovar, D.I. et al. (1994) Transplant Production Systems Influence Growth and Yield of Fresh-market Tomatoes. J. Am. Soc. Hortic. Sci. 119, 662-668

34 Mulyati et al. (2009) Root pruning and transplanting increase zinc requirements of canola (Brassica napus). Plant Soil 314, 11-24

35 Condon, A.G. et al. (2004) Breeding for high water-use efficiency. J. Exp. Bot. 55, 24472460

36 Pohlmeier, A. et al. (2008) Changes in soil water content resulting from Ricinus root uptake monitored by magnetic resonance Imaging. Vadose Zone J. 7, 1010-1017

37 Lecompte, F. et al. (2008) Root and nitrate distribution as related to the critical plant $\mathrm{N}$ status of a fertigated tomato crop. J. Hortic. Sci. Biotechnol. 83, 223-231

38 Machado, R.M.A. et al. (2000) Effect of drip irrigation and fertilization on tomato rooting patterns. Acta Hortic. 537, 313-320

39 Maria do Rosario, G.O. et al. (1996) Tomato root distribution under drip irrigation. J. Am. Soc. Hortic. Sci. 121, 644-648

40 Wiesler, F. and Horst, W.J. (1994) Root growth and nitrate utilization of maize cultivars under field conditions. Plant Soil 163, 267-277

41 Sandhu, N. et al. (2016) Rice Root Architectural Plasticity Traits and Genetic Regions for Adaptability to Variable Cultivation and Stress Conditions. Plant Physiol. 171, 2562-2576 
42 Bar-Yosef, B. et al. (1980) Growth of Trickle-Irrigated Tomato as Related to Rooting Volume and Uptake of $\mathrm{N}$ and Water. Agron. J. 72, 815-822

43 Nestler, J. et al. (2016) Root hair formation in rice (Oryza sativa L.) differs between root types and is altered in artificial growth conditions. J. Exp. Bot. 67, 3699-3708

44 Garnett, T. et al. (2009) Root based approaches to improving nitrogen use efficiency in plants. Plant Cell Environ. 32, 1272-1283

45 Hodge, A. (2004) The plastic plant: root responses to heterogeneous supplies of nutrients. New Phytol. 162, 9-24

46 Mori, A. et al. (2016) The role of root size versus root efficiency in phosphorus acquisition in rice. J. Exp. Bot. 67, 1179-1189

47 Brown, L.K. et al. (2013) Interactions between root hair length and arbuscular mycorrhizal colonisation in phosphorus deficient barley (Hordeum vulgare). Plant Soil 372, 195-205

48 Keyes, S.D. et al. (2013) High resolution synchrotron imaging of wheat root hairs growing in soil and image based modelling of phosphate uptake. New Phytol. 198, 1023-1029

49 Bengough, A.G. et al. (2016) Root hairs aid soil penetration by anchoring the root surface to pore walls. J. Exp. Bot. 67, 1071-1078

50 Zhu, J. et al. (2010) The utility of phenotypic plasticity of root hair length for phosphorus acquisition. Funct. Plant Biol. 37, 313-322

51 Robinson, D. (1994) The Responses of Plants to Nonuniform Supplies of Nutrients. New Phytol. 127, 635-674

52 York, L.M. et al. (2016) Spatiotemporal variation of nitrate uptake kinetics within the maize (Zea mays L.) root system is associated with greater nitrate uptake and interactions with architectural phenes. J. Exp. Bot. 67, 3763-3775

53 Aibara, I. and Miwa, K. (2014) Strategies for optimization of mineral nutrient transport in plants: multilevel regulation of nutrient-dependent dynamics of root architecture and transporter activity. Plant Cell Physiol. 55, 2027-2036

54 Gross, K.L. et al. (1993) Fine root growth and demographic responses to nutrient patches in four old-field plant species. Oecologia 95, 61-64

55 Pregitzer, K. et al. (1993) The Demography of Fine Roots in Response to Patches of Water and Nitrogen. New Phytol. 125, 575-580

56 Fransen, B. and de Kroon, H. (2001) Long-Term Disadvantages of Selective Root Placement: Root Proliferation and Shoot Biomass of Two Perennial Grass Species in a 2Year Experiment. J. Ecol. 89, 711-722

57 Vetterlein, D. and Doussan, C. (2016) Root age distribution: how does it matter in plant processes? A focus on water uptake. Plant Soil DOI: 10.1007/s11104-016-2849-6

58 Clarkson, D.T. (1985) Factors Affecting Mineral Nutrient Acquisition by Plants. Annu. Rev. Plant Physiol. 36, 77-115

59 Carminati, A. et al. (2016) Biophysical rhizosphere processes affecting root water uptake. Ann. Bot. DOI: 10.1093/aob/mcw113

60 Segal, E. et al. (2008) Microsensing of water dynamics and root distributions in sandy soils. Vadose Zone J. 7, 1018-1026

61 Brown, L.K. et al. (2012) What are the implications of variation in root hair length on tolerance to phosphorus deficiency in combination with water stress in barley (Hordeum vulgare)? Ann. Bot. 110, 319-328

62 Zygalakis, K.C. et al. (2011) A dual porosity model of nutrient uptake by root hairs. New Phytol. 192, 676-688 
63 Carminati, A. et al. (2010) Dynamics of soil water content in the rhizosphere. Plant Soil 332, 163-176

64 Ahmed, M.A. et al. (2014) Mucilage exudation facilitates root water uptake in dry soils. Funct. Plant Biol. 41, 1129-1137

65 Holz, M. et al. (2016), Effect of soil water content on spatial distribution of root exudates and mucilage in the rhizosphere. , presented at the EGU General Assembly Conference Abstracts, 18, pp. 9731

66 Carminati, A. et al. (2016), Rhizosphere biophysics and root water uptake. , in $E G U$ General Assembly Conference Abstracts, Vienna, 18, pp. 9079

67 Bronick, C.J. and Lal, R. (2005) Soil structure and management: a review. Geoderma 124, 3-22

68 Groppa, M.D. et al. (2012) Root hydraulic conductance, aquaporins and plant growth promoting microorganisms: A revision. Appl. Soil Ecol. 61, 247-254

69 Feeney, D.S. et al. (2006) Three-dimensional Microorganization of the Soil-Root-Microbe System. Microb. Ecol. 52, 151-158

70 Augé, R.M. (2004) Arbuscular mycorrhizae and soil/plant water relations. Can. J. Soil Sci. 84, 373-381

71 Augé, R.M. (2001) Water relations, drought and vesicular-arbuscular mycorrhizal symbiosis. Mycorrhiza 11, 3-42

72 Bowles, T.M. et al. (2016) Effects of arbuscular mycorrhizae on tomato yield, nutrient uptake, water relations, and soil carbon dynamics under deficit irrigation in field conditions. Sci. Total Environ. 566, 1223-1234

73 Belimov, A.A. et al. (2009) Rhizosphere bacteria containing 1-aminocyclopropane-1carboxylate deaminase increase yield of plants grown in drying soil via both local and systemic hormone signalling. New Phytol. 181, 413-423

74 Goh, C.-H. et al. (2013) The impact of beneficial plant-associated microbes on plant phenotypic plasticity. J. Chem. Ecol. 39, 826-839

75 Lindsay, M.P. et al. (2004) A locus for sodium exclusion (Nax1), a trait for salt tolerance, mapped in durum wheat. Funct. Plant Biol. 31, 1105-1114

76 Barrett-Lennard, E.G. (2003) The interaction between waterlogging and salinity in higher plants: causes, consequences and implications. Plant Soil 253, 35-54

77 Colmer, T.D. et al. (2005) Improving salt tolerance of wheat and barley: future prospects. Aust. J. Exp. Agric. 45, 1425-1443

78 Munns, R. et al. (2002) Avenues for increasing salt tolerance of crops, and the role of physiologically based selection traits. Plant Soil 247, 93-105

79 Thorup-Kristensen, K. and Kirkegaard, J. (2016) Root system-based limits to agricultural productivity and efficiency: the farming systems context. Ann. Bot. DOI: 10.1093/aob/mcw122

80 Doussan, C. et al. (2003) Soil exploration and resource acquisition by plant roots: an architectural and modelling point of view. Agronomie 23, 419-431

81 York, L.M. et al. (2016) The holistic rhizosphere: integrating zones, processes, and semantics in the soil influenced by roots. J. Exp. Bot. DOI: 10.1093/jxb/erw 108

82 Oburger, E. and Schmidt, H. (2016) New Methods To Unravel Rhizosphere Processes. Trends Plant Sci. 21, 243-255

83 Fereres, E. and Soriano, M.A. (2007) Deficit irrigation for reducing agricultural water use. J. Exp. Bot. 58, 147-159 
84 Ayars, J.E. et al. (2015) Subsurface drip irrigation in California-Here to stay? Agric. Water Manag. 157, 39-47

85 Cassman, K.G. et al. (2002) Agroecosystems, Nitrogen-use Efficiency, and Nitrogen Management. AMBIO J. Hum. Environ. 31, 132-140

86 Sun, Y.Q. et al. (2013) Drying/rewetting cycles of the soil under alternate partial root-zone drying irrigation reduce carbon and nitrogen retention in the soil-plant systems of potato. Agric. Water Manag. 128, 85-91

87 Schipper, L.A. et al. (2013) Decadal Changes in Soil Carbon and Nitrogen under a Range of Irrigation and Phosphorus Fertilizer Treatments. Soil Sci. Soc. Am. J. 77, 246-256

88 Wang, Y.S. et al. (2010) Carbon retention in the soil-plant system under different irrigation regimes. Agric. Water Manag. 98, 419-424

89 Wang, Y.S. et al. (2010) Alternate partial root-zone irrigation induced dry/wet cycles of soils stimulate $\mathrm{N}$ mineralization and improve N nutrition in tomatoes. Plant Soil 337, 167177

$90 \mathrm{Li}, \mathrm{X}$. et al. (2010) Soil microbial response, water and nitrogen use by tomato under different irrigation regimes. Agric. Water Manag. 98, 414-418

91 Subbaiah, R. (2013) A review of models for predicting soil water dynamics during trickle irrigation. Irrig. Sci. 31, 225-258

92 Snyder, R.L. et al. (2015) Advances in ET-based landscape irrigation management. Agric. Water Manag. 147, 187-197

93 Phogat, V. et al. (2012) Modelling soil water and salt dynamics under pulsed and continuous surface drip irrigation of almond and implications of system design. Irrig. Sci. 30, 315-333

94 Phogat, V. et al. (2013) Evaluation of soil plant system response to pulsed drip irrigation of an almond tree under sustained stress conditions. Agric. Water Manag. 118, 1-11

95 Dunbabin, V. et al. (2003) Is there an optimal root architecture for nitrate capture in leaching environments? Plant Cell Environ. 26, 835-844

96 Haling, R.E. et al. (2013) Root hairs improve root penetration, rootsoil contact, and phosphorus acquisition in soils of different strength. J. Exp. Bot. 64, 3711-3721

97 Corneo, P.E. et al. (2016) Effect of twenty four wheat genotypes on soil biochemical and microbial properties. Plant Soil 404, 141-155

98 Cocking, E.C. (2003) Endophytic colonization of plant roots by nitrogen-fixing bacteria. Plant Soil 252, 169-175

99 Novero, M. et al. (2009) Root Hair Colonization by Mycorrhizal Fungi. In Root Hairs pp. 315-338, Springer Science \& Business Media

100 Kuzyakov, Y. and Blagodatskaya, E. (2015) Microbial hotspots and hot moments in soil: Concept \& review. Soil Biol. Biochem. 83, 184-199

101 Lugtenberg, B. and Kamilova, F. (2009) Plant-Growth-Promoting Rhizobacteria. Annu. Rev. Microbiol. 63, 541-556

102 He, X.-H. et al. (2003) Nitrogen Transfer Within and Between Plants Through Common Mycorrhizal Networks (CMNs). Crit. Rev. Plant Sci. 22, 531-567

103 Watts-Williams, S.J. and Cavagnaro, T.R. (2014) Nutrient interactions and arbuscular mycorrhizas: a meta-analysis of a mycorrhiza-defective mutant and wild-type tomato genotype pair. Plant Soil 384, 79-92 
497 Key Figure 1. A comparison of irrigated and rainfed ideotypes. Differences in resource

498 distribution between rainfed and irrigated environments pose the need for an alternative set of 499 root phenes. The irrigated ideotype emphasizes investment in the water- and nutrient-rich zone 500 around the water source, with shallower axial roots of varied angles and lateral foraging 501 restricted to the wetting zone. Transplant vigor and salinity tolerance represent traits unique to 502 the irrigated environment. The inclusion of rhizosphere interactions is a novel addition to 503 ideotype breeding. Integration of the traits proposed here could guide creation of resource504 efficient cultivars for irrigated systems.

505

506 Glossary

507 Deficit irrigation (DI): application of a reduced volume of water, typically 60-100\% of crop 508 evapotranspiration [83]

509 Fertigation: simultaneous delivery of irrigation water and dissolved fertilizer

510 Furrow irrigation: delivery of water between crop rows

$511 K_{m}$ : transporter affinity for its substrate

512 Micro-irrigation: surface or subsurface technologies that deliver water to the root zone, often

513 increasing yield and irrigation water productivity [84]

514 Nitrogen use efficiency (NUE): "The proportion of all $\mathrm{N}$ inputs that are removed in harvested

515 crop biomass, contained in recycled crop residues, and incorporated into soil organic matter and 516 inorganic $\mathrm{N}$ pools" [85]

517 Partial root-zone drying (PRD): application of water to alternate sides of the root system when 518 soil water content reaches a specified level [86]

519 
520 Proliferation: the initiation of new lateral roots rather than the elongation of existing roots;

521 species- and context-dependent [45]

522 Root length density (RLD): $\mathrm{cm}$ root length $/ \mathrm{cm}^{3}$ soil

523 Specific root length (SRL): $\mathrm{cm}$ root length/g root mass

$524 V_{\max }$ : maximum uptake rate of a transporter

525 Water productivity: yield, economic, social, and ecosystem benefits produced per unit of water 526 used [8]

527 Water use efficiency (WUE): "The yield of harvested product achieved from the water made 528 available to the crop through precipitation and/or irrigation" [35]

530 Box 1. Environment-specific tradeoffs of component traits

531 A key aspect of the irrigated ideotype is that it must be tailored to its environment to minimize

532 undesirable tradeoffs (see Table I) in terms of metabolic cost, foraging ability, responsiveness,

533 and nutrient uptake. Soil characteristics such as resource availability and compaction establish

534 the framework for cost-benefit analyses specific to each root trait. For instance, in a compacted

535 and intensively managed system with high inorganic $\mathrm{P}$ availability, carbon investment in shallow

536 lateral root proliferation could be more advantageous than root hair development and recruitment

537 of microbes that solubilize organic P. Long-lived and highly vesseled roots could increase

538 nutrient transport but might compromise rapid foraging responses to capture nutrient pulses; the

539 former strategy being most attractive when resources are homogeneous and abundant. While

540 determining the relative benefit of traits for each specific soil environment represents an increase

541 in complexity over a universal ideotype, this approach could help maximize resource use

542 efficiency. 


\section{Box 2. The complexity of irrigated environments}

545 Labeling agricultural systems as merely "rainfed" or "irrigated" admittedly oversimplifies the

546 substantial diversity within contemporary irrigated agriculture as well as within rainfed systems

547 experiencing different precipitation patterns. While a full discussion of the intricacies of

548 irrigation technologies is beyond the scope of this review, it is critical to acknowledge that

549 differences in frequency, location, and amount of water application generate distinct wetting

550 patterns across time and space, which may subsequently affect nutrient distribution, microbially-

551 mediated biogeochemical cycling, and beneficial root traits for resource capture.

552 - Frequency: Irrigation frequency is typically higher in micro-irrigated than furrow-

553 irrigated systems, allowing for more precise adjustment of irrigation volume to match

554 crop demand, increased yields, and decreased percolation and leaching losses [84]. When

555 irrigation occurs often enough to prevent crop stress, $\mathrm{C}$ mineralization may not be

$556 \quad$ affected by slight variations in frequency [87].

557 - Location: Partial root-zone drying (PRD) shows how concentrated wetting zones may

558 increase WUE but can incur negative tradeoffs as compared to even moisture. The more

559 extreme wet-dry cycles in PRD increase $\mathrm{C}$ and $\mathrm{N}$ mineralization $[86,88,89]$, accelerating

560 losses of nutrients and organic matter. Depth of irrigation also affects yield and soil

561 parameters, with subsurface micro-irrigation improving yields but potentially

562 contributing to higher salinity in the root zone as compared to surface micro-irrigation

$563 \quad[84]$.

564 - Volume: Deficit irrigation (DI) can increase water productivity and nitrogen use

565 efficiency, but may increase microbial $\mathrm{C} / \mathrm{N}$ ratios [90]. By favoring fungi over bacteria, 
DI could potentially decrease bacterial-mediated $\mathrm{C}$ and $\mathrm{N}$ cycling, but long-term studies of soil health indicators such as organic matter content and microbial activity are needed for a more comprehensive cost-benefit analysis of DI.

570 High-resolution description of effects of variation in frequency, location, and volume at the scale

571 encountered by roots throughout a growing season is necessary to improve understanding of how

572 ideal root traits may vary between irrigated systems (Outstanding Questions). Modeling studies

573 can complement field-level studies by predicting variation in water, nutrient, and salinity

574 dynamics for system-specific plant, soil [91] and microclimatic [92] characteristics at scales

575 relevant to roots and crop growth cycles. For instance, models such as HYDRUS-2D can more

576 accurately and cost effectively predict variations in salinity and water distribution between

577 pulsed versus continuous [93] and deficit versus full [94] drip-irrigated almond compared to field

578 studies. Applying similar approaches to annual crops could help understand how root

579 exploitation of the wetting zone varies with growth stages, a topic that has not received sufficient 580 attention due to the difficulty of high-frequency and non-destructive field monitoring. Modeling

581 approaches incorporating variations in soil and microclimatic characteristics at a rhizosphere-

582 relevant scale should be used to compare wetting zones and wet-dry cycles between irrigated and

583 rainfed systems or between irrigation technologies at a given location.

\section{Box 3. The potential of integrating rhizosphere functions into ideotypes}

586 Although microbial associations are rarely included in ideotypes, root traits supporting active 587 microbial communities could contribute to efficient water and nutrient acquisition and 588 improvements in soil structure. Potential for microbial associations is determined in part by root 
589 system characteristics such as presence of fine roots [97] while root hairs are involved in

590 colonization by $\mathrm{N}$-fixing bacteria [98] and arbuscular mycorrhizal fungi (AMF) [99]. The extent

591 of colonization may therefore be affected by interactions with host genotype, resource

592 availability, soil compaction, and other factors that drive morphological development. Root

593 turnover and mucilage could represent an important source of labile carbon in low-carbon

594 environments [100]. Likewise, exudation of organic compounds feed microbial communities that

595 fix and cycle various forms of $\mathrm{N}$ [101], solubilize phosphorus [101], improve macro- and

596 micronutrient uptake [101], and translocate $\mathrm{P}$ and $\mathrm{N}$ to crops through hyphal networks [102].

597 However, exudates that promote microbial associations represent a significant investment of

598 photosynthate and their contribution to plant nutrient status is likely greatest in lower-input or

599 deficient systems [103] or for acquisition of immobile nutrients in the resource-depleted wetting

600 zone. Rhizodeposition of organic carbon that stimulates organic matter decomposition (i.e.

601 priming effects) could release additional nutrients but may incur hidden tradeoffs for soil organic

602 matter formation and carbon sequestration which remain unclear. In intensively managed

603 systems with high nutrient availability, microbial enhancement of soil structure through

604 exopolysaccharide production and hyphal binding of aggregates may represent a greater

605 contribution to crop resource acquisition by promoting water availability and uptake.

606 Rhizosphere processes may be even more important in irrigated than rainfed systems

607 because localized water inputs overlap with carbon sources supplied by roots, providing the

608 conditions necessary for microbial "hotspots" of intense activity and resource cycling [100].

609 Recruitment of beneficial bacteria may be facilitated by more constant soil moisture that

610 increases the range of microbial mobility. Additional research on specific spatial and temporal

611 patterns of microbial activity in irrigated systems is required, particularly in the rhizosphere. A 
612 better understanding of genetic variation for exudate quantity and quality; the heritability of 613 microbial community composition, activity, and function; and critical cost-benefit analysis of 614 rhizosphere investment in intensively managed systems would aid the integration of these traits 615 in breeding programs.

616 
618 Table I. Potential tradeoffs associated with ideotype traits

\begin{tabular}{|c|c|c|}
\hline Category & Trait & Tradeoffs \\
\hline \multirow[t]{3}{*}{ Morphology } & $\begin{array}{l}\text { Few axial roots with varied } \\
\text { angles }\end{array}$ & $\begin{array}{l}\text { Reduced patch exploitation in any single } \\
\text { direction and/or capture of mobile nutrients } \\
\text { below wetting zone }\end{array}$ \\
\hline & $\begin{array}{l}\text { Plastic, localized and prolific } \\
\text { lateral root proliferation }\end{array}$ & $\begin{array}{l}\text { Maladaptive when resources are very } \\
\text { heterogeneous due to construction and } \\
\text { maintenance cost }[80,95]\end{array}$ \\
\hline & & $\begin{array}{l}\text { Restricted foraging outside wetting zone could } \\
\text { limit immobile resource availability }\end{array}$ \\
\hline \multirow[t]{3}{*}{ Anatomy } & Long, dense root hairs & $\begin{array}{l}\text { Construction and maintenance costs; less } \\
\text { beneficial in compacted soil due to already high } \\
\text { root-soil contact [96] }\end{array}$ \\
\hline & Aerenchyma formation & $\begin{array}{l}\text { Aerenchyma may decrease lodging resistance } \\
\text { [17] and radial water and nutrient transport [18] }\end{array}$ \\
\hline & $\begin{array}{l}\text { Endodermal barrier } \\
\text { development }\end{array}$ & Potential impacts on nutrient transport \\
\hline \multirow[t]{4}{*}{ Physiology } & $\begin{array}{l}\text { Inducible transporters and } \\
\text { aquaporins }\end{array}$ & $\begin{array}{l}\text { Manipulation of transporters might not result in } \\
\text { improved } \mathrm{N} \text { acquisition [44], feedback } \\
\text { regulation mechanisms }\end{array}$ \\
\hline & $\begin{array}{l}\text { High } \mathrm{V}_{\max } \text { for nitrate and } \\
\text { ammonium transporters; low } \\
\mathrm{K}_{\mathrm{m}} \text { for immobile nutrients }\end{array}$ & $\begin{array}{l}\text { Potential tradeoffs with plasticity vs. optimal } \\
\mathrm{V}_{\max } \text { or } \mathrm{K}_{\mathrm{m}}\end{array}$ \\
\hline & $\begin{array}{l}\text { Low root turnover near } \\
\text { wetting boundary }\end{array}$ & $\begin{array}{l}\text { May decrease responsiveness to localized } \\
\text { resource availability }\end{array}$ \\
\hline & Mucilage exudation & $\begin{array}{l}\text { Cost of production; becomes hydrophobic if } \\
\text { dehydrated [63] }\end{array}$ \\
\hline Biology & $\begin{array}{l}\text { Production and exudation of } \\
\text { microbial substrates }\end{array}$ & $\begin{array}{l}\text { Substantial carbon investment may not be worth } \\
\text { the cost in intensive systems }\end{array}$ \\
\hline
\end{tabular}




\section{Outstanding Questions}

- Could the generalized irrigated ideotype be improved by tailoring it to specific crops? Crop-specific versions of this irrigated ideotype likely have to be developed by integrating information about unique adaptive traits and root structure. A large number of annuals with distinct root structures are grown in irrigated systems while orchard ideotypes might require additional deep roots for physical stability. Rootstock ideotypes could also factor in characteristics such as disease resistance, which might be of greater relative importance in long-lived perennials.

- Are irrigation-system-specific traits necessary? While this irrigated ideotype seeks to combine traits generally applicable across different irrigation systems, zones of resource distribution, microbial activity, and salt accumulation may differ depending on subsurface drip, sprinkler, furrow, and flood irrigation, timing of irrigation and interaction with other management practices. As a result, system-specific traits are likely required.

- Can partial root-zone drying (PRD) enhance resource use efficiency, and if so, how could it be integrated into an ideotype? Applying water to one side of the root zone while the other is allowed to dry is hypothesized to increase resource use efficiency, but PRD is not currently widely applied. The potential benefits warrant further analysis of the effect of PRD on root architecture and uptake rates as well as the soil microbial community.

- How can breeding programs enhance plant-microbe interactions in an irrigated context? Plant-microbe interactions can contribute substantially to resource acquisition, but knowledge of how they are affected by irrigation is limited and the extent of genetic variation and heritability for microbial associations remains to be characterized. Modeling studies of irrigation systems and crop roots have not included soil microorganisms as a parameter. 
- What are the implications of integrating ecosystem functions into an agricultural ideotype?

Roots are important drivers of carbon sequestration, nitrogen cycling, and other ecosystem processes, but it is unclear how these roles could be integrated into an ideotype and what the potential tradeoffs would be. 


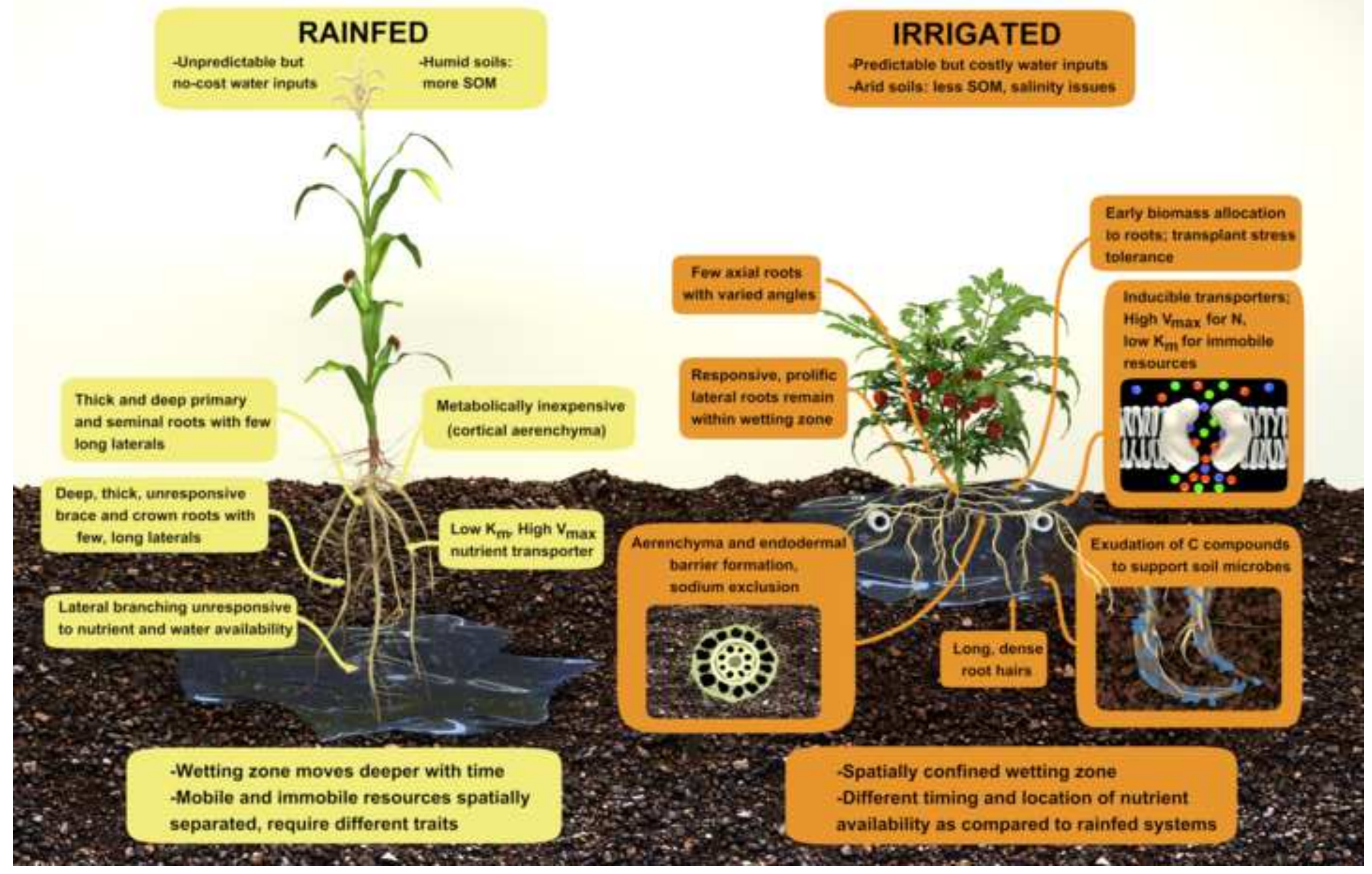

